\title{
LANGUAGE PERCEPTION AND LANGUAGE PRODUCTION IN EARLY CHILDHOOD: LANGUAGE ACQUISITION
}

\author{
Vivi Velanitta \\ IAIN Ponorogo \\ e-mail:vvellanita@gmail.com
}

Keywords:

acquisition, language

perception, language

production, mistake, error.

\begin{abstract}
A B S T R A C T
Language acquisition is a term to define the process of gaining language ability naturally and subconsciously. In language acquisition, there is an optimal time for children to acquire language. The time is known as the critical period. When the critical time has passed by the children without language contact, it will be (almost) impossible for the children to acquire first language and be the native of second language. On the other hand, while children acquire language, they will make mistakes (often) and error (rarely). It is related how the children perceive language and the way they produce it. In reference to developing language in human, this paper will explore theoretical frameworks related with the steps of childhood language acquisition related with the transformational process of language perception into language production.
\end{abstract}

\section{INTRODUCTION}

Every normal human use language in their daily activities as a means of communication. Spolsky (1998) states that, one of the principals uses of language is to communicate meaning, but it is also used to establish and to maintain social relationships. It means that the use of language in daily life has two purposes: to communicate meaning and maintain social relationships. To communicate meaning means language is used for delivering information as a message from the speaker to the audience. Communication can be called successful if the information is well accepted and generates a response from the audience. The second function of language is relating within a social context. This statement is also supported by Hassan (2011) who states that language has two functions. The first is the main function of language which is used by humans to communicate to others. The second function is language exists in a social world in which it fulfills communicative functions. The source (speaker) sends a message and information to the receiver (listener) by using a signaling system (Crystal, 1997). The signal can be defined as language if it has meaning and makes contact with the outside world (Bolinger and Sears, 1981).

Language is an abstract system that consists of processes in linking biology and neurology. In producing language, the brain, as the neurological process, takes control how the language is perceived, and the body, as the biological process, takes control how the language is produced. Beyond the neurological and biological processes, Abonyi (2011) states that language is a mean of initiating the child into the culture of his people. This contact process is dependent upon the children's environment which influences the success of language development. Without people around the children language skills will not fully develop. 
Early childhood is the most optimal time to acquire language. Starting from birth, a baby starts to deliver signal to people around him/ her. The signals which is send will be develop by the time, as same as the development of the brain and vocal apparatus. To know when and how humans acquire and use the real language, this paper will explore theoretical frameworks related with the steps of early children language acquisition related with the process of brain and vocal apparatus development and the influence of the environment on creating the language system.

\section{A. THE NOTION OF LANGUAGE ACQUISITION}

Language acquisition explains the stages children experience for developing competent language skills (Agbedo in Abonyi 2011). The term is commonly used to define a condition when humans acquire language without a learning process. It happens naturally and subconsciously (Krashen, 2009). The process of language acquisition happens not only in the term of expressing utterances but also the process of building mental grammar. The acquisition of mental grammar is the result of language and the experience provided by environment. It indicates that every human doesn't only have the ability in acquiring language but also brain capacity for grammar acquisition (Ritchie and Bhatia, 2008). The brain capacity of each human is flexible so it is possible for humans to acquire more than one language at a time, depending upon environmental influences and support

First language acquisition refers to the way children learn their native language. It is called mother tongue (Krashen, 2009). Second language acquisition is a term used to define the process by which people acquire a second language in addition to their native language. It is also used to describe the acquisition of any language that is done after the acquisition of the mother tongue (Yule, 2006). Children can acquire both first and second languages if they have normal brain capacity and also environment supports. A child who acquires more than one language is called a bilingual.

Language acquisition is natural for humans, but the environment also takes part in creating language systems. Human beings are predisposed to speak a language because they were born with LAD (Language Acquisition Device) that makes the human available to speak with others (Chomsky: 1994). On the other hand, Skinner in Krashen (2009) states that language is a set of habits that grows over the years. There is no mental mechanism needed because the environment will create the system. These two theories oppose each other. Examining the strengths and the weaknesses of the two theories, Slobin in Lightbown and Spada (2006) tries to combine them. Although human has LAD, but the interaction with the social context is needed. Slobin says that human has LAD supports them in making creative language, but the environment also plays an important place in acquiring basic language. That is why a baby born whose brain capacity still needs environment as the model to develop language ability, and the brain is needed to use language creatively.

\section{B. CRITICAL PERIOD HYPOTHESIS}

Lightbown and Spada (2006) argue that ability of using language in humans is acquired within a specific time. When the time has passed without acquiring a language, it would be almost impossible to get the ability in future the time when humans are able to acquire language is 
called the critical period hypothesis. In the critical period, a language can be acquired naturally (Ellis in Nikolov, 2002) because at that time the plasticity of the brain is in ideal condition to accept language (Penfield and Robert in Nikolov, 2002). The critical period, also known as the sensitive period for language acquisition, happens in early childhood, roughly happening between age two until puberty when the left brain which controlling the language becomes specialized. The specialized function of the brain is called lateralization. After the lateralization is completed, first language (L1) acquisition would be impossible and L2 acquisition would be fundamentally different. (Lenneberg in Nikolov, 2002; Yule, 2006; Arabski and Wojtaszek, 2010) the difference in the second language acquisition after the critical period passed is on the accent that the speakers use.

There are several steps in language acquisition during the critical period time. Aitchinson (2011) explains some steps in the table below:

Table 1. Language Stages in Critical Period

\begin{tabular}{|l|l|}
\hline Language stage & Beginning age \\
\hline Crying & Birth \\
Cooing & 6 weeks \\
Babbling & 6 months \\
Intonation patterns & 8 months \\
Oneword utterances & 1 year \\
Twowword utter ances & 18 mon ths \\
Word inflections & 2 years \\
Questions, negatives & $2 \%$ years \\
Rare or complex constructions & 5 years \\
Mature speech & w years \\
\hline
\end{tabular}

A child passes through 10 steps to developing a native language. The steps in the first three years are called milestone period. Lightbown and Spada (2006) state that the first three years of children is called the "milestone time" because in this time, children learn how to use their speech organ to express the utterances. The actual age at which children reach each stage or milestone may vary, but the sequence remains the same (Larsen and Freeman, 2009). In the milestone time, the key stages are: (1) Vocalization (crying, cooing, babbling, and intonation pattern); (2) holophrastic and, (3) telegraphic. While after three years, the stages passed are called the morphemic and transformational stages, consisting of the processing and developing language into its complex structures and constructions (Steinberg,1990; Yule, 2006; Aitchinson, 2011).

\section{Vocalization}

Vocalization is a period when new babies express their feelings by using sounds, although the sounds have no meaning. Babies worldwide will vocalize this even if they are deaf (Stenberg, 1990). During the vocalization time, children will exhibit crying, cooing, babbling, and imitating intonation patterns.

A baby first language stage is crying. Although crying is not a real speaking activity, crying is still called a "language phase" because crying is instinctively done by children when they want to express feelings for example, various cries can be detected. Babies will cry when they are hungry, uncomfortable with wet diapers, or feeling pain. By crying, physically baby is able to express the utterances (Lester and Boukydis in Aitchinson, 2011) 
Cooing is also known as gurgling. This stage happens in a 6-week-old baby. The baby starts to express feelings by using "no meaning" sound. At this age, a baby's speech organ is not developed enough to build a language (except to cry). Cooing is a sound produced when the baby automatically strengthens their muscles by kicking their legs and moving their arms. Cooing may help the baby to gain control over the vocal apparatus. The cooing usually happens when a baby feels happy and satisfied. The meaningless words that are produced may be "GOOGOO", or "AAA". Taine in Aitcinson (2011) states that a baby coos like a bird, only twittering with no meaning but expression of joy.

At six months, the baby's vocal muscle becomes stronger. The baby starts to produce sound by repeating consonant-vowel combination (Steinberg, 1990). The consonants produced are often made with the lips, or the teeth, so that the sequences sound like "MA-MA", "DI-DI", "BABA" or "PA-PA". This phase is called babbling (Tracy in Aitchinson, 2011). Simultaneously with babbling, and from around eight or nine months, a baby begins to imitate intonation patterns. In this stage, a baby often uses a question intonation, with a rise in tone at the end of the sentence. In intonation patterns, baby shows what kind of native they will be. Different with the stages passed before, this stage indicates whether the hearing organ is normal or not. In case of deaf babies, they will not through this stage (Aitchinson, 2011).

\section{Holophrastic}

Holophrastic is also known as naming or a one-word utterance. At this stage, children start to say their first word which is connecting with the object (Steinberg, 1990). It shows that the babies' language is well developed (Stoel-Gammon and Cooper in Aitchinson, 2011). At this time, the babies start to produce single words as the result of language development in the brain and the sometimes what the babies said will be different with the right pronunciations increasing ability of vocal muscle (Yule, 2006). Here, babies start to know what they speak and try to imitate adult about thing they know, such as "woof" to say Dog, or Daba to "Grandma". The baby has perceptions and wants to express them in the words, but the speech organs have not truly support it yet so. It happens roughly when the babies are a year old (Aitchinson, 2011).

\section{Telegraphic}

By the second birthday, babies enter the telegraphic stage which includes reaching the more impressive two words stage, word inflection, and also improving the ability of using negation and question. Clark (2009) in the end of the first year, children seem to be representing what they hear in memory. They start to express utterances by using their language knowledge. From the time, baby started to put words together and seemed to be in a state of language readiness. At this age, a baby learns vocabulary and tries to combine them in utterances. Bates in Aitchinson (2011) provides explanations related this stage. In the early part of the two-word stage, when the baby was around 2 years old, Babies' speech was telegraphic. The baby sounded as if she/ he was sending urgent telegrams to her mother: WANT MILK, WHERE DUCK? As in a real telegram, the baby tended to preserve the nouns and verbs in the correct order, but omitted the little words such as articles, conjunctions, and prepositions. The baby also left out word endings, such as the plural -S or past tense -D, as in TWO SHOE and MILK SPILL. (Steinberg, 1990). This statement is in line with telegraphic stage in which babies is already able to utter two-word stage. 
After children gain the ability in combine words, they start to use the words to negate and ask questions. In the negation stage, children realize that they can use "no" to reject something they don't like, such as "No eat" or "no touch" (Lightbown and Spada (2006) In addition, children's' ability to ask questions also increases. They will ask questions related to their interests. At first, the questions may only be one or two words, "Cookie?" or "Mama book?", but after that they will start to use the question words such as "what's that". They also will learn how to use declarative sentences and finally they will learn and be able to use why and yes/no questions, the negatives forms of question sentences (Lightbown and Spada, 2006; Aitcinson, 2011). In the telegraphic stages, the children will use grammar inconsistently. Nasrin (2008), the Nativist theory, says that childrens' language at any stage is systematic. They produce sentences containing all of the components of any grammar. In the process of telegraphic, the children will combine two or some words to send an urgent message. While they learn to combine words, they also learn how to use the correct grammar subconsciously. At the telegraphic stage, children will also able to make a negotiation. Negotiations include: restating, clarifying, and confirming information. In the milestone, it will vary one to another related with when and how they do negotiation (Gang, Davidson and Lyons, 2008).

\section{Morphemic and Transformational Stages}

Morphemic and transformational are terms used to define the stages when the child produces longer utterances, use the word, and more complex syntactic structure (Steinberg, 1990). Another statement is by Hickmann (1986) who states that children acquire a sign system which bears important relationships in both knowledge and social parts in their life. They use language to fulfill communication process. By the age four, the children will be able to ask questions, give command, report real events, and imaginative story by using correct words and grammatical marker (Lightbown and Spada, 2006). At the age eight to ten, children will be natives of language which is also known as mature of speech (Aitchinson, 2011). At that age children will enter school be able to use language in specific context, for example: telling a joke and make a trap question. The children will also use language creatively. Tin (2010) says, the term language creativity or creative language use, is defined as the playful use of language to construct new/unknown meanings, transforming ones current linguistic and conceptual world and involving several types of creative thinking. The children will be able to feel whether what they utter is in good order and logically acceptable. At that time, the metalinguistic awareness also improves well (Lightbown and Spada, 2006).

\section{ACQUIRING PROCESS}

\section{Language Perception and Language Production}

In Acquiring language, children need ability, called aptitude and attitude. Language aptitude is defined as an innate, relatively fixed, talent to acquire and process language structure. It is related with the plasticy of brain in processing language. (Bylund, et al., 2009). In other hand, attitude also influencing the acquiring process. Attitude is related with the personality of the acquirers and their orientation to the language ( Krashen, 2002). A high level and good combination between aptitude and attitude makes the children easier and faster in acquiring, both the first language and/ or second language.

Another part human needs to be able using language is input. Input is provided by the environment. Goffman in Argaman (2008) argues that when an individual interacts with others, 
he or she does so in a manner that suits his or her social role. It also happens in language acquisition. Children need to interact with others to get input in their mind, or which is called language perception (Nikolov, 2002). Sharing Time, which may also be known as Circle Time or Show and Tell", will really help the children to acquire language because the children can get a good input to build a good language perception while they interact to others (Willen, 2008).

Griffin and Ferreira (2006) argue that in producing language, it is needed at least three main steps, there are: deciding what to express (conceptualization), determining how to express it (formulation), and expressing it (articulation). This statement is supported by Atkinson (2010) who states in producing language, the cognition, perception, and motor action are integrated activities which cannot be separated each other. The children will use their brain to draw a perception before they produce it by using speech organ (motor action).

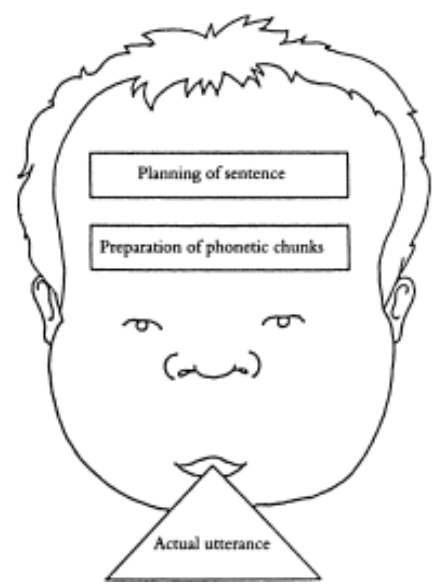

Picture 1: Language Production Process

While Ingram (2007) states that we only need two steps in using language, that are speech production and perception. Speech perception comes from a specialized perceptual-motor system of mirror neurons, located in the prefrontal cortex (Brocas area), but with intimate connections to the superior temporal gyrus, lies at the basis of imitative capabilities for speech and gestural communication in human beings, while speech production is an automatic process of neural apparatus to move humans body in producing signal.

Although there is a little difference between the language production process, but the experts deal with the argument that before the utterance is produced, a mental process in the brain is needed. The mental process is called perception, while the utterance is called language production.

\section{Errors vs. Mistakes}

In the early childhood, children will learn how to use their vocal apparatus. Sometimes what in their perception is produced by different utterance. As the caretakers, parents have to clarify to make sure whether what the children say is an error or only a mistake. Ellis (1997: 17) states that error reflects gaps between knowledge and performance. While mistakes mean lapses because failed to perform what they know. Most of the children are in the second type, they do mistakes. It happens because their vocal organ is not developed perfectly yet so they failed to speak or pronounce some lexical words and/ or what in their mind. The differences between 
language perception and language production in mistakes are also known as lapses. In the lapses, children have correct language perception but fail in language production caused by physical factor. A little of them also do errors. The errors they did are caused by imperfect imitating process. The children only imitate the young without knowing what the real meaning is and they do both of failed to imitate and also do not understand about what they say. In other words, they produce incorrect language with no correct perception about it.

To make sure whether the "mispronounce" is mistake or error, the caretaker have to actively check it and help the children to make it right before the fossilization happens. Eskildsen (2008) states that people's skill in using language is depend on memorized chunks. The caretakers have responsibility to help the children to improve their memory and avoid them to save wrong perception about the use of language from the early childhood because the children formulate and store language norms detached from the situations and environment in which they are embedded (Canagarajah and Wurr, 2011). Dai and Sternberg (2004) also argues that practice aimed at improving performance with appropriate sub goals. By giving time and let the children get enough practice in using language, it will really help to improve children's language development.

The process of hearing and recast mistakes did by children is the best way to help them (Krashen, 2009). While recast is the way the younger helps the children to make correct utterance by repeating the mistakes into the correct one as often as possible until the children are capable to use the correct one. To correct the children's error, which is rarely happens in early childhood but it is not impossible, only give them the brief explanation about what they do not understand yet, so there.

\section{CONCLUSION}

Language acquisition is a time when children get language ability naturally and subconsciously. Both of brain capacity and the society takes control to develop children language acquisition. Society will create the basic of language while the brain will work as a tool of language processing unit to make the children able to use language creatively.

Critical period is crucial for the children in acquiring language. It is begun when the children are born and end when the brain finish its specialized function, roughly in children's puberty. In language acquisition in early childhood, there are some steps passed by the normal children. The main steps are: vocalization, holophrastic, telegraphic, and morphemic and transformational process.

While acquiring language, children will find the difficulties to express what is on their mind. It is called mistakes, when they failed to perform what they think because the vocal apparatus is not develop perfectly yet. In other word, it is a little difference in transformational process of language perception into language production (lapses). It does not indicate that the children did not understand about what they speak. As the caretaker, parents can help it by using here and now and recast process. Besides, error happens when the children only produce incorrect utterance by imitating others without having a perception about the word. It can be help by giving them explanation and understanding about it. 


\section{REFERENCES}

Abonyi. (2011). The Language Acquisition Schedule: The Igbo Language Example. Journal of Igbo Language and Linguistics no. 3, 35-42

Aitchinson, Jean. (2011). The Articulate Mammal: An Introduction to Psycholinguistics. New York: Rotledge Classics

Arabski, Janusz and Adam Wojtaszek. (2010). Neurolinguistic and Psycholinguistic Perspective on SLA. Great Britain: Short Run Press Ltd

Argaman, Einav. (2008). In Same Boat? On Methapor Variation as Mediating the Individual Voice in Organizational Change. Applied Linguistics 29: 3, 483- 502

Atkinson, Dwight. (2010). Extended, embodied Cognition and Second Language Acquisition. Applied Linguistics 31:5, 599-622

Blythe, richard A., and Wiliam A. Croft in Eliss, Nick C and Diane Larsen Freeman. (2009). Language is a Complex Adaptive System. Michigan: university of Michigan.

Bolinger, Dwigth and Sears, Donald. (1981). Aspect of Language. United States of America: Harcourt Brace Jovanovich, Inc

Bylund, Emanuel., Niclas Abrahamsson, and Kenneth Hyltenstam. (2009). The Role of Language Aptitude in first Language Attrition: The Case of Pre-pubescent Attriters. Applied Linguistics 31:3, 443-464

Canagarajah Suresh and Adrian Wurr. (2011). Multilingual Communication and Language Acquisition: New Research Directions. The Reading Matrix 11: 1， 1-15

Chen, Chuntien and John Truscott. (2010). The effect of Repetition and L1 Lexicalization on Incidental Cocabulary Acquisition. Applied Linguistics 31:5, 693-713

Chomsky, Noam. (1997). Language and Thought. United States of America: Moyer Bell.

Clark, Eve V. (2009). First Language Acquisition (2nd Edition). New York: Cambridge University Press

Crystal, David. (1997). A Dictionary of Linguistic and Phonetics. United Kingdom: Blackwell Publishers Ltd.

Dai, David Yun and Robert J. Sternberg. (2004). Motivation, Emotion and Cognition. New Jersey: Lawrence Erlbaum Associates Publisher

Ellis, Rod. (1997). Second Language Acquisition. New York: Oxford University Press

Eskildsen, Soren W. (2008). Constructing another Language-Usage Based Linguistics in Second Language Acquisition. Applied Linguistics 30:3, 335-357

Gan, Zhengdong, Chris Davidson, and Liz Hamp Lyons. (2008). Topic Negotiation in Peer group Oral Assesment Situations: A Conversational Analitytic Approach. Applied Linguistics 30:3, 315-334

Griffin, Zenzi M., and Victor S. Ferreira in Traxler, Matthew J., and Morton A. Gernsbacher. (2006). Handbook of Psycholinguistics (2nd Edition). New York: Elsevier 
Hassan, Shahid. (2011). Language Development Hinges on communication: An Emergentist Perspective. TESOL Journal 2: 4, 510-520

Hickmann, Maya in Fletcher, Paul and Michael Garman. (1986). Language Acquisition: Studies in First Language Development (2nd Edition). Great Britain: Cambridge University Press

Housen, Alex and Folkert Kuiken. (2009). Complexity, Accuracy, and Fluency in Second Language Acquisition. Applied Linguistics 30:4, 461-473

Ingram, John C. (2007). Neurolinguistics: An Introduction to Spoken Language Processing and Its Disorders. New York: Cambridge University Press

Krashen, Stephen D. (2002). Second Language Acquisition and Second Language Learning. California: Pergamon Press Inc

(2009). Principle and Practice in Second Language Acquisition. California: University of Suothern California

Larsen, Diane and Freeman. (2009). Adjusting Expectations: The Study of Complexity, Accuracy, and Fluency in Second Language Acquisition. Applied Linguistics 30:4, 579-589

Lightbown, Patsy and Nina Spada. (2006). How Languages are Learned (3rd Edition). New York: Oxford University Press

Margana. (2015). Establishing English-Indonesian Bilinguals in Indonesia: From Theory to Practice. RA Journal of Applied Research 1:10,365-374

McKay, L. Sandra and Hornberger, H. Nancy. (1996). Sociolinguistic and Language Teaching. New York: Cambridge University Press

Nasrin, Sadia. (2008). First Language Acquisition: Grammar in the Speech of a Two- Year Old Bangladeshi Child. BRAC University Journal, 5: 2, 121-124

Nikolov, Marianne. (2002). Issues in English Language Education. Bern: Peter Lang

Ritchie Wiliam C., and Tej K. Bhatia in Spolsky, Bernard and Francis M. Hult. (2008). The Handbook of Educational Linguistics. Victoria: Blakwell publishing Ltd

Steinberg, Danny D. (1990). Psycholinguistics: Language, Mind and World. New York: Longman Inc

Tin, Tan Bee. (2010). Language Creativity and Co-emergence of Form and Meaning in Creative writing Task. Applied Linguistics 32:2, 215-235

Tomasello, Michael. (2005). A Language. London: Cambridge University Press

Widdowson, H. G. (2005). Principle \& Practice in Applied Linguistics. New York: Oxford University Press

Willen, Polly Bjork. (2008). Routine Trouble: How Prescool Children Participate in Multilingual Instruction. Applied Linguistics 29: 4, 555-577

Yule, George. (2006). The Study of Language (3rd Edition). Cambridge: Cambridge University Press 